\title{
Voucher Privatization: A Detour on the Road to Transition?
}

\author{
Barbara G. Katz ${ }^{1} \quad$ Joel Owen ${ }^{2}$
}

May 14, 2001

${ }^{1}$ Professor of Economics, Stern School of Business, New York University, 44 West 4th Street, New York, NY 10012; tel: 212998 0865; bkatz@stern.nyu.edu; corresponding author

${ }^{2}$ Professor of Statistics, Stern School of Business, New York University, 44 West 4th Street, New York, NY 10012; tel: 212998 0446; jowen@stern.nyu.edu 


\begin{abstract}
Voucher Privatization: A Detour on the Road to Transition?

More than ten years after the fall of the Berlin Wall, the assessment of the progress achieved by the Czech Republic and Poland differs from the interim appraisals. Since the transition paths differed, the question arises as to how the methods of privatization might have contributed to the subsequent performances of the respective economies. We investigate the theoretical problems that voucher privatization poses and contrast them with the alternative Polish mutual fund approach to mass privatization. We study the problem facing individuals who invest their vouchers in voucher privatization funds (VPFs) which, in turn, are able to use their skills to alter the performances of the firms in which they acquire shares. The VPFs have different skills and by their bids, and subsequent joint ownership patterns, affect the performances of the firms in their funds. We show that even in the case in which voucher holders have identical and full information, and wish to allocate their vouchers to the VPFs in a manner consistent with the maximization of economy-wide profit, a coordination failure generally prevents the implementation of this efficient outcome. Uncertainty, as well as differing payouts by the VPFs, is shown to exacerbate the problem. We conclude that the initial conditions of voucher privatization are flawed and provide a theoretical basis for preferring the Polish to the Czech method of privatization.

Journal of Economic Literature categories: P21, L33, D44, G11

Key Words: Economics of transition, voucher privatization, voucher privatization funds, voucher investment funds, corporate governance
\end{abstract}




\section{Voucher Privatization: A Detour on the Road to Transition? ${ }^{\sharp}$}

\section{Introduction}

More than ten years after the fall of the Berlin Wall, the general assessment of the progress achieved by the Czech Republic and Poland differs substantially from the interim appraisals. ${ }^{1}$ The prevailing current view is that the Czech Republic, by engaging in voucher privatization in the manner in which it pioneered, gave the appearance early-on that it had found a good recipe for privatization and hence transition; later results, however, showed the Czech approach to be significantly flawed, and the Czech transition was somewhat derailed as a consequence. On the other hand, Poland, which did not emulate the Czech voucher privatization program, was long considered a laggard in privatization, but now is recognized as perhaps the leading exponent of successful transition. ${ }^{2}$ In contrast to the Czech Republic, Poland delayed the privatization of its firms, and only later proceeded with its mutual fund based approach to privatization that did not involve the public in investment decision-making.

Since the transition paths that these two countries chose differed substantially, the general question naturally arises as to how the methods of privatization might have influenced the subsequent performances of the respective economies. Within this very broad and important question is a more narrowly defined one: is there something inherent in voucher privatization that is inimical to the further development of markets and hence successful transition? Our paper addresses this question by investigating the theoretical problems that voucher privatization presents and contrasting them with the alternative Polish approach to mass privatization.

\footnotetext{
${ }^{1}$ These reversals in evaluation began in the summer of 1997. See Stiglitz (1999) for a critical evaluation of voucher privatization and the "Washington Consensus" ten years after the beginning of the transition.

${ }^{2}$ For an early view that is more bullish on the Polish rather than the Czech program, see Katz and Owen (1997).
} 
To do this, we develop and analyze a model of voucher privatization that includes the essential features of the Czech program. ${ }^{3}$ These essential features include, first, that there was only one moment in time, the "zero round," at which individuals were permitted to decide how to divide their voucher points between those that they would bid themselves and those that they would exchange for shares in voucher privatization funds (VPFs). ${ }^{4}$ Second, that VPFs became the dominant players in the auctions for ownership of firms. ${ }^{5}$ Third, that the share ownership obtained as a result of a particular bid was proportional to the total number of voucher points being bid for the fraction of the firm being offered for sale. Fourth, that increased ownership in a firm permitted the VPFs to have greater involvement in the management of the firm.

We find that, even in the case in which voucher holders have identical and full information, a coordination failure arises that would prevent the VPFs from achieving their investment goals. Specifically, we show that because of the presence of multiple equilibria of the noncooperative game played by voucher holders, there is no mechanism that will induce the voucher holders to allocate their vouchers to the VPFs in a way that implements the unique profit-maximizing equilibrium in the subsequent non-cooperative game played by the VPFs. This is despite the fact that the voucher holders agree, in this case, that the division of the vouchers between the funds that is in their best interests is the one that maximizes economywide profit. The Polish plan, in contrast, did not suffer from these problems. Our stylized

\footnotetext{
${ }^{3}$ We use "Czech" to refer also to Czechoslovakia and the Czech and Slovak Federal Republic when appropriate.

${ }^{4}$ The "zero round" preceeded the more well-publicized series of "rounds" in which some attempts were made to adjust prices for cases in which there was significant excess demand or excess supply. See van Wijnbergen and Marcincin (1995), Frydman, Rapaczynski, Earle, et al (1993), and Hingorani, Lehn and Makhija (1997).

${ }^{5}$ The VPFs acquired $72 \%$ of the voucher points in the first 1992 privatization, and $64 \%$ of the points in the second wave. See Coffee (1996, p. 136).
} 
analysis of the Czech voucher privatization program, and our subsequent comparison of it with the Polish program, leads us to conclude that the problems we have uncovered in the voucher privatization process may have been responsible for at least some of the differences in the performances of these two economies.

Our focus is on studying the implications that arise as a consequence of the distribution of vouchers among VPFs. That is, no matter what the potential skill of a VPF, unless it attracted vouchers from the initial voucher holders, it could not bid in the voucher auctions. ${ }^{6}$ We investigate the conditions under which the initial voucher holders could align their voucher investments in accordance with the skills of the VPFs. We believe that the role played by the decisions that led to the voucher endowment of each VPF has been overlooked in the literature. Empirical analyses of the impacts of VPFs on profitability or corporate governance are, of necessity, conditioned on the particular distribution of voucher between funds. But what are the properties of the distribution of the vouchers between funds? One of our contributions is to show that there is no mechanism that guarantees that the distribution of vouchers between funds of different skill levels will be such that the profits of the firms in which the funds acquire shares will be maximized. The inference we draw is that the initial conditions of voucher privatization are flawed.

The longer term impact of these flawed initial conditions is the subject of much debate in the literature. Some argue that voucher privatization is just the first step in a process of change from state to private ownership and that any mistakes will be rectified in the capital markets. Others argue that the secondary markets cannot be depended upon to provide the appropriate corrections, and find more fault with the design of the voucher privatization

\footnotetext{
${ }^{6}$ It is this fact, in particular, which immediately distinguishes the analysis of voucher schemes from that of portfolio problems in which borrowing or lending is permitted.
} 
programs themselves. ${ }^{7}$ We see our results as lending theoretical support to this more critical view of privatization, and as providing a theoretical basis for preferring the Polish mutual fund approach to the Czech voucher privatization program.

The literature on voucher privatization is substantial. Some of the works are descriptive, while others are empirical. ${ }^{8}$ All the empirical studies, by definition, consider the distribution of vouchers as given, and study what proceeded from that given distribution. Being interested in exploring the nature of the process that leads to the initial distribution of vouchers to the funds, we do not survey the empirical findings. However, one can find a comprehensive review of this literature in Megginson and Netter (2000).

The theoretical side of voucher privatization has been virtually ignored. This paper builds on Katz and Owen (1997) which considers the behavior of an arbitrary number VPFs, having already received vouchers from the public, and differing in their ability to manage and restructure the firms in which they have bid for and acquired shares. As in the empirical work on this subject, Katz and Owen take the initial distribution of vouchers among the VPFs as given, and show that the bidding process may fail to align the skills of the VPFs with share ownership. We go beyond that here, showing that a coordination failure generally will preclude individuals from allocating their vouchers to funds in a way that will enable the funds to maximize the sum of the profits of the firms whose shares they buy. Our work highlights the importance of the initial distribution of vouchers among the VPFs on both the performances of the firms in which they acquire ownership, and on the economies in which these firms function.

\footnotetext{
${ }^{7}$ See Stiglitz (1999) for a discussion on the failure of the "aftermarket" to improve on the results of the voucher privatizations.

${ }^{8}$ For descriptive sources relating to the Czech experience see Coffee (1996), Boycko, Shleifer and Vishny (1994), and Frydman, Rapaczynski and Earle et al. (1993).
} 
The plan of this paper is as follows. In Section 2 we provide brief overviews of the voucher privatization approach and the mutual fund approach to mass privatization. In Section 3 we present our model of voucher privatization, which includes individual voucher holders, VPFs, and firms available for privatization. The problem facing the VPFs, conditional on having received vouchers from the individual voucher holders, is stated and solved in Section 4. Section 5 follows with the solution to the portfolio investment problem facing the individual voucher holders, and investigates the implications of the solution on economy-wide profit. The impact of uncertainty on the solution is also investigated in this section. In the final Section we close with a discussion that includes a comparison of alternative mass privatization plans.

\section{Overview of Voucher Privatization and Mutual Fund Privatization}

\subsection{Voucher Privatization}

Political realities prevented economies in transition from employing conventional privatization methods. In opting instead for mass privatization programs, several countries, including the Czech Republic and Russia, chose to use vouchers to facilitate the transfer of assets from state to private ownership. An essential component of all of these programs is that vouchers, rather than domestic currency, are designated as the currency in which auctions for the formerly state-owned enterprises are conducted. In this context, prices do not perform their traditional roles. ${ }^{9}$

\footnotetext{
${ }^{9}$ Although there are similarities between the Russian and Czech voucher privatization programs, we concentrate on the Czech voucher privatization process. This decision was made, in part, because in Russia only a minority $(29 \%)$ of the shares in participating enterprises was offered for sale by the voucher method, whereas in the Czech Republic it was almost the entire firm (97\%). Because of insider privatization, the Russian experience has limited application. Also, the centralized system in the Czech Republic, in which all firms being privatized were offered for auction at the same time, was not followed in Russia. Instead, the privatization
} 
The reasons to bypass the ordinary domestic currency were several: the lack of adequate capital in the hands of the public, the lack of a functioning capital market, the belief that this populist program would serve as a successful midwife to the capitalist economy by actively encouraging the population to participate in the new economic framework, and, not least of all, the desire to disenfranchise those who had acquired a disproportionate share of the outstanding domestic currency by profiting from illegal activities under the prior regime.

Since both equity and widespread participation in the voucher programs were sought, an equal allocation of vouchers, denominated either in points or currency, was made available to each citizen at a nominal cost. In the Czech Republic the vouchers were denominated in points, and were not tradeable, only being valuable in exchange for shares in firms being privatized. Once an individual had paid a nominal fee and had acquired his or her allocation of vouchers, the individual had the choice of either directly submitting his or her own vouchers for shares in the firms being offered for privatization, or of exchanging those vouchers for shares in financial intermediaries, which would then bid for shares in the auction.

In the "zero round" in the Czech program, no information on prices was available to the investors as the price per share of all vouchers was administratively set at 3 shares per 100 voucher points. Adjustments to prices came only later, in subsequent rounds, and therefore process was decentralized (localized), with auctions being held in different physical locations. The structure of employing a series of "rounds" and attempting to produce a tatonnement process also was not used in Russia; rather, the auctions were of the one shot-kind. See Boycko, Shleifer and Vishny (1995, p. 100) for a discussion of the appearance of VPFs in Russia in the summer of 1993; they eventually numbered approximately 600. A further distinction between the two countries' plans was that vouchers could be alienated in the Russian case, although not in the Czech case. We note that in Russia, and after the zero round in the Czech Republic, bids by individuals competed at auction with the bids of the VPFs. Finally, in Russia, an alternate type of bid in which the buyer was able to specify a reservation price in shares per voucher was permitted; however, less than $2 \%$ of the bidders used this option. Again, see Boycko, Shleifer and Vishny (1994, 1995). 
had no impact on individuals' choices of executing the vouchers themselves or exchanging them for shares in financial intermediaries.

Intermediaries made their first appearance during the Czech voucher privatization program, and became a standard feature of subsequent voucher privatizations. ${ }^{10}$ By February 1992, when Czech citizens were first able to execute their vouchers, more than 400 investment privatization funds, what we call here VPFs, had come into existence. ${ }^{11}$ Discussions at the time focused attention on two roles that the VPFs might play: providing investors the ability to diversify their holdings and ensuring that ownership would not be as widely distributed as the vouchers, thus encouraging improved corporate governance. ${ }^{12}$ Quite quickly, the VPFs in the Czech privatization program became the dominant players in the market, gathering the

\footnotetext{
${ }^{10}$ The development of these financial intermediaries is curious. During 1990-1991, when the legal machinery for privatization was being debated and developed by the Czech government, many alternative plans were discussed, only some of which included financial intermediaries. By February 1991, when the government issued the Large Scale Privatization Act, it gave voucher holders the right to use their vouchers directly in auctions, or to use their vouchers through intermediares called investment privatization funds. At that time, however, no investment privatization funds existed, and the Act said little about them; indeed, the government really did not know whether or not they would emerge. If they were to emerge, the government wanted that to happen spontaneously, and without government direction or participation. To this end, the government kept regulation of these potential intermediaries to a minimum. Thus, the Czech Large Scale Privatization Act merely permitted investment privatization funds, if they emerged, to take part in the voucher privatization process.

${ }^{11}$ VPFs were set up by banks, corporations and individuals, which established management companies to operate the funds. Most fund managers were rewarded by receiving a percentage of assets under management that was capped at $2 \%$. Although it was possible for the management contract to be of a profit-sharing nature, this was not the choice of most managers. See Weiss and Nikitin (1999).

${ }^{12}$ See, for example, the discussions of this point in Coffee (1996, p. 124), Weiss and Nikitin (1999, p. 1) and Stiglitz (1999, p. 11).
} 
bulk of the vouchers. ${ }^{13}$ Indeed, they are sometimes credited with generating the enthusiasm within the population without which voucher privatization could not have been successfully completed. ${ }^{14}$

While VPFs resemble western closed-end mutual funds in that they both acquire and then manage portfolios of firms, VPFs differ from conventional mutual funds in a non-trivial way: VPFs were able to take an active role in managing and restructuring the firms in which they purchased shares. This possibility permitted the VPFs to be vehicles for improving corporate monitoring and performance in a situation in which widespread initial voucher distribution, and hence potential share ownership, was desirable for political reasons. Much of the subsequent reevaluation of the merits of voucher privatization is derived from differing assessments of how well, or if at all, the VPFs performed these tasks.

Minimal regulation of the VPFs led to exaggerated claims concerning anticipated returns in order to entice individual voucher holders to exchange their vouchers for those of a given VPF. Lack of regulation also contributed to fraud. Consequently, as voucher programs got underway, regulations relating both to advertising claims and VPF registration were typically introduced. ${ }^{15}$

We identify four important features of the Czech voucher privatization process that will be used in the model below: (1) the notion of a "zero round," (2) that VPFs obtained the bulk of the vouchers, (3) that the share of ownership obtained as a result of a particular bid was proportional to the total number of voucher points being bid for the fraction of the firm offered for sale, ${ }^{16}$ and (4) that increased ownership in a firm permitted the VPFs to increase

\footnotetext{
${ }^{13}$ See Coffee (1996, p. 124).
}

${ }^{14}$ See Coffee (1996).

${ }^{15}$ For a discussion of the role of Victor Kozeny and Harvard Capital and Consulting, see, for example, Coffee (1996).

${ }^{16}$ Note that this proportionality applied to the initial voucher holders, as they exchanged their voucher 
their involvement in the management of the firm. Although there were certain restrictions placed on ownership by VPFs, we do not model them. ${ }^{17}$

\subsection{Mutual Fund Approach}

Poland chose a different method of mass privatization, one that did not include the distribution of vouchers to the population. From the start, the Polish plan sought to insure that each enterprise had a core investor with the incentive to take an active role in monitoring and restructuring the firm. Thus, the pattern of ownership of the participating firms, and its subsequent implications for corporate governance, was not left to be determined by a voucher bidding process. ${ }^{18}$ In the Polish plan, the government appointed fifteen national investment funds (NIFs) to be run by mixed local and foreign-owned securities firms. ${ }^{19}$ In random order, points for shares in the VPFs, as well as to the VPFs, as they subsequently bid for shares in the auctions of the firms.

${ }^{17}$ In particular, regulations subsequent to the Czech Large Scale Privatization Act, but before the February 1992, "zero round," restricted VPFs from investing more than $10 \%$ of their capital in any one firm and from owning more than $20 \%$ of the nominal value of the securities of any one firm. Banks, because they could set up more than one VPF, could actually control larger percentages of the firms in which they acquired shares than these numbers would indicate. See Coffee (1996, p.128). In fact, additional regulations in March 1992, stipulated that, besides limiting a fund to own no more than $20 \%$ of the securities of any one firm being privatized, if an investment company administered several funds, it could hold no more than $40 \%$ of any firm being privatized in its entire portfolio. See Frydman, Rapaczynski, Earle et al. (1993) p. 88. For restrictions in Russia, see Frydman, Rapaczynski, Earle et al (1993) and Frydman, Pistor and Rapaczynski (1996, pp. 193-194).

${ }^{18}$ The Polish mass privatization plan was introduced in late 1995, after a lengthly political process, and concerned a smaller number of enterprises (513), than the voucher plans. See Sachs (1993) and Grosfeld (1996) for descriptions of the plan.

${ }^{19}$ The foreign participants were selected from among well-known foreign securities firms based on their reputations and performance histories. 
each NIF was entitled to select an enterprise for which it would be designated the lead fund, receiving in this capacity $33 \%$ of the shares of that firm; each NIF became the lead fund for approximately 30 firms. The selection process continued until the $33 \%$ block of shares of each participating enterprise was in the hands of a lead NIF. Of the remaining shares of the firm, $27 \%$ were equally divided and distributed to the other NIFs, the government retained $25 \%$ of the shares of each firm, and $15 \%$ of the shares were earmarked for the employees.

For a nominal fee, citizens were able to acquire a certificate giving them an equal share in each of the NIFs. In essence, citizens could obtain an "imputed voucher" representing their share in the privatized assets, but without having the ability either to bid directly for shares of the privatized firms, or to exchange their vouchers for shares in particular voucher privatization funds. Thus, decisions by individuals played no direct role in the resulting ownership structure of the NIFs. Only later were the Poles to be able to unbundle ("dematerialize") these imputed vouchers and rebalance their holdings in accordance with individual optimization choices.

\section{Description of the Model of Voucher Privatization}

We consider a transition economy that has decided to privatize the ownership of its stateowned enterprises in an effort to improve economy-wide economic performance. Since the method of effecting the transfer of assets will have significant implications for the resulting ownership profile, and hence for corporate governance and economic efficiency, the choice of a particular privatization strategy, as well as its technical implementation, is an important one. We suppose that for any number of reasons, including political ones related to issues of equity, the method of mass privatization via a voucher scheme that includes VPFs has been selected.

Accepting that, in theory, conventional privatization is efficient since it relies on auctions, 
what can be said about this alternative method of voucher privatization? For example, Boycko, Shleifer and Vishny (1994, p. 250) argue against the viability of conventional privatization in Eastern Europe and the former Soviet Union, but also claim that mass privatization "does not entail abandoning the quest for improving the efficiency of firms," and that "[b]ased on the cases of the Czech and Russian voucher privatizations...politically feasible programs can also be made attractive from the viewpoint of economic efficiency." As we show below, this optimistic supposition is likely to be unfounded.

In our paper we model a one-shot voucher privatization program and study the problem from the point in time when individuals decide on the division of their vouchers between those that they will execute themselves and those that they will invest in VPFs. Consequently, an important feature of our model is that prices were not available at the time of decision making. To make the problem more tractable, and to capture the fact that the VPFs were the dominant players in the voucher privatization process, we assume that all individuals decide to invest all their vouchers in VPFs, so that the problem for them becomes one of choosing the particular VPF in which to invest. We could have included the possibility of the investor wishing to keep control over his or her own vouchers, but this would have complicated the analysis without adding to the intuition. We note that we suppress any distinction in our model between a VPF and its management company, treating them as one entity. We also assume that the VPFs have different skills in managing and restructuring the firms in which they acquire shares, and that they acquire ownership shares in the firms being privatized in proportion to their bids. The ultimate ownership in each firm by the VPF, although unknown at the time of the auction, is assumed to affect performance. ${ }^{20}$

\footnotetext{
${ }^{20}$ The behavior of Czech banks provides ample evidence that ownership was thought to matter at this time: The banks took an exceptionally active role in acquiring vouchers from individual investors and subsequently bidding them to acquire ownership in firms that would then have an impact on the banks' performances.
} 
We now turn to the question of whether, in theory, voucher privatization leads to the maximization of the sum of the profits of the firms being privatized. If and when conditions lead to the maximization of this sum of profits, we say that voucher privatization produces an efficient outcome.

The model we propose has two voucher holders who must decide how to invest their vouchers in two investment funds that, in turn, will use the vouchers to bid to acquire ownership in two firms. Importantly, the profitability of each firm depends on the specific joint ownership structure that results from the vouchers each VPF receives, as the funds are assumed to have different management capabilities.

We start by assuming that $N>0$ privatization vouchers have been distributed at zero cost to the population which consists of two individuals, $I_{1}$ and $I_{2}$. Voucher holder $I_{l}, l=1,2$, has received $V_{l}>0$ vouchers where $V_{1}+V_{2}=N$. The number of vouchers held by each individual may differ to allow the possibility of pre-auction trading. Each $I_{l}$ must decide independently on the number of vouchers to invest in each of two voucher privatization funds, $F_{j}, j=1,2$. The number of vouchers that $I_{1}$ chooses to allocate to $F_{1}$ is denoted by $x, x \in\left[0, V_{1}\right]$, with the remaining $V_{1}-x$ vouchers being allocated to $F_{2}$. Similarly, we denote by $y, y \in\left[0, V_{2}\right]$, the voucher investment of $I_{2}$ in $F_{1}$, with $V_{2}-y$ being invested in $F_{2}$. As a consequence of investing its vouchers in this manner, $I_{1}$ acquires the proportion $\frac{x}{(x+y)}$ of the profit of $F_{1}$ and $\frac{\left(V_{1}-x\right)}{\left(V_{1}-x\right)+\left(V_{2}-y\right)}$ of the profit of $F_{2}$. Correspondingly, $I_{2}$ acquires the proportion $\frac{y}{(x+y)}$ of the profit of $F_{1}$ and $\frac{\left(V_{2}-y\right)}{\left(V_{1}-x\right)+\left(V_{2}-y\right)}$ of the profit of $F_{2}$. The general case when the number of voucher holders, the number of privatization funds, and the number of investments are arbitrary may be handled in a similar manner to the development below, but at a cost of greater complexity.

At the outset, neither $F_{j}$ has any vouchers. In order to attract vouchers from the $I_{l}$, each $F_{j}$ reveals information useful to the $I_{l}$. We assume that this information relates to the cost 
structure of the $F_{j}$. Specifically, we assume that each $F_{j}$ announces that its costs will be a fixed proportion of the revenues it will earn by investing the vouchers that it will acquire. ${ }^{21}$ This assumption is equivalent to the assumption that the profit of the $F_{j}$ is equal to $\delta_{j} R_{j}(x+y)$ where $\delta_{j}$ is constant, $\delta_{j} \in[0,1], j=1,2$, and $R_{j}: \Re_{+} \rightarrow \Re_{+}$is the revenue received by $F_{j}$ as a result of the bidding game in which, using vouchers acquired from the $I_{l}, F_{1}$ and $F_{2}$ compete to acquire shares in the firms offered for privatization. The $\delta_{j}$ can be thought of as the proportion of revenue that the $F_{j}$ promise to distribute to the share holders. $R_{1}(x+y)$ depends on $x+y$ since this is the number of vouchers available to $F_{1}$ for investment in firms to be privatized. Similarly, $R_{2}(x+y)$ has the same dependence since the total number of vouchers, $N$, is fixed.

Thus $I_{1}$ receives $m_{1}: \Re_{+}^{2} \rightarrow \Re_{+}$where

$$
m_{1}(x, y)=\frac{x}{x+y} \delta_{1} R_{1}(x+y)+\frac{V_{1}-x}{\left(V_{1}-x\right)+\left(V_{2}-y\right)} \delta_{2} R_{2}(x+y)
$$

and $I_{2}$ receives $m_{2}: \Re_{+}^{2} \rightarrow \Re_{+}$where

$$
m_{2}(x, y)=\frac{y}{x+y} \delta_{1} R_{1}(x+y)+\frac{V_{2}-y}{\left(V_{1}-x\right)+\left(V_{2}-y\right)} \delta_{2} R_{2}(x+y)
$$

$I_{1}$ chooses $x$ to maximize $m_{1}$ and $I_{2}$ chooses $y$ to maximize $m_{2}$. We refer to these problems as the voucher investment problem (VIP). In what follows, we take $x$ and $y$ to be continuous over their respective ranges.

The $R_{j}(x+y)$ are determined by the following process. With $N_{1}=x+y$ and $N_{2}=N-N_{1}$ shares respectively, $F_{1}$ and $F_{2}$ play a non-cooperative game in which they submit bids to acquire shares in firm $i, i=1,2$. Each $F_{j}$ submits a voucher bid of $a_{i j}$ in firm $i$ where $a_{i j} \geq 0$ and $\sum_{i} a_{i j}=N_{j}$. As a consequence of the bidding, each $F_{j}$ receives the proportion $p_{i j}=\frac{a_{i j}}{\sum_{j} a_{i j}}$

\footnotetext{
${ }^{21}$ That differences in costs may exist among the $F_{j}$ is justified by the assumption, made below, that skills differ among the $F_{j}$.
} 
of $\pi_{i}$, the profit of firm $i$. We assume that the $\pi_{i}: \Re_{+}^{2} \rightarrow \Re_{+}, i=1,2$, depend on $p_{i j}, j=1,2$, that is, we assume that the $F_{j}$ have different skills in managing and restructuring the firms in which they have acquired shares, and that their ability to implement these skills varies with the proportion of ownership achieved via the bidding game. ${ }^{22}$ In particular, we assume that the profits that result from the joint ownership of firms by funds with differing skill levels are given by:

$$
\pi_{1}=k_{1}+p_{11} d_{11}+p_{12} d_{12}=k_{1}+d_{12}+p_{11}\left(d_{11}-d_{12}\right)=k_{12}+p_{11} \Delta_{1}
$$

and

$$
\pi_{2}=k_{2}+p_{21} d_{21}+p_{22} d_{22}=k_{2}+d_{21}+p_{22}\left(d_{22}-d_{21}\right)=k_{21}+p_{22} \Delta_{2}
$$

where $p_{i 1}+p_{i 2}=1$ and where the $k_{j} \in[0, \infty)$ are the expected profit of the firm before the bidding game, the $d_{i j}$ represent the skill level of $F_{j}$ in firm $i$ and $\Delta_{i}$ represents the differential improvement contributed by $F_{i}$ in firm $i$. We note that since the $p_{i i}$ depend on $x+y$, the $\pi_{i}$ depend on $x+y$ also. For subsequent use, we define $\pi_{i}(z)=k_{i j}+z \Delta_{i}$. Thus, after having submitted their bids, $F_{j}$ receives the revenue

$$
p_{1 j} \pi_{1}\left(p_{11}\right)+p_{2 j} \pi_{2}\left(p_{22}\right) \text {. }
$$

The revenue accruing to $F_{j}$ at the Nash equilibrium of the bidding game is what we call $R_{j}\left(N_{1}\right)$ and thus the profit available for distribution to the $I_{l}$ is $\delta_{j} R_{j}\left(N_{1}\right)$ where $N_{1}=x+y$.

We assume that both $I_{l}$ share the same information set concerning the firms and skill levels, as well as the reasoning and characteristics of the $F_{j}$. Since the $R_{j}\left(N_{1}\right)$, the results of

\footnotetext{
${ }^{22}$ Although some evidence has been presented for a nonlinear relationship between profitability and ownership concentration (see Claessens and Djankov (1999) for example), this nonlinear component becomes important only when the percentage of ownership is large, typically greater than one-half. However, in the case of voucher privatization, legal restrictions kept the percentage of ownership below .4, justifying the linear assumption.
} 
the bidding game between the $F_{j}$, are required by the $I_{l}$ to solve their problem, we investigate this bidding game first.

\section{The Voucher Fund Problem}

We now formalize the noncooperative bidding game played by the $F_{j}$. Given $N_{1}$ and $N_{2}$, and given the bids of $F_{j^{\prime}}, j^{\prime} \neq j, F_{j}$ must choose its bids to maximize its profit. Since, by earlier assumption, its profit is a fixed multiple of its revenue, $F_{j}$ 's bids must satisfy

$$
\max _{a_{1 j}, a_{2 j}} \sum_{i} p_{i j} \pi_{i}\left(p_{i i}\right)
$$

subject to $a_{i j} \geq 0$ and $\sum_{i} a_{i j}=N_{j}$, and where $p_{i j}=\frac{a_{i j}}{\sum_{j} a_{i j}}$. We refer to these programs as the voucher fund problem (VFP).

The Lagrangian for $F_{1}$ is

$$
L_{1}=p_{11} \pi_{1}\left(p_{11}\right)+p_{21} \pi_{2}\left(p_{22}\right)-\lambda_{1}\left(a_{11}+a_{21}-N_{1}\right)
$$

with first-order conditions:

$$
\begin{gathered}
\frac{\partial L_{1}}{\partial a_{11}}=0=\frac{\left(1-p_{11}\right)}{a_{1} \bullet} \pi_{1}+p_{11} \frac{\left(1-p_{11}\right)}{a_{1}} \Delta_{1}-\lambda_{1}=\frac{\left(1-p_{11}\right)}{a_{1} \bullet}\left(\pi_{1}+p_{11} \Delta_{1}\right)-\lambda_{1} \\
\frac{\partial L_{1}}{\partial a_{21}}=0=\frac{\left(1-p_{21}\right)}{a_{2} \bullet} \pi_{2}-p_{21} \frac{p_{22}}{a_{2} \bullet} \Delta_{2}-\lambda_{1}=\frac{p_{22}}{a_{2} \bullet}\left(\pi_{2}-\Delta_{2}+p_{22} \Delta_{2}\right)-\lambda_{1} \\
\frac{\partial L_{1}}{\partial \lambda_{1}}=0=a_{11}+a_{21}-N_{1}
\end{gathered}
$$

where $a_{i \bullet}=\sum_{j} a_{i j}$.

Similarly, the Lagrangian for $F_{2}$ is

$$
L_{2}=p_{12} \pi_{1}\left(p_{11}\right)+p_{22} \pi_{2}\left(p_{22}\right)-\lambda_{2}\left(a_{12}+a_{22}-N_{2}\right)
$$

with first-order conditions:

$$
\frac{\partial L_{2}}{\partial a_{12}}=0=\frac{\left(1-p_{12}\right)}{a_{1} \bullet} \pi_{1}-p_{12} \frac{p_{11}}{a_{1} \bullet} \Delta_{1}-\lambda_{2}=\frac{p_{11}}{a_{1} \bullet}\left(\pi_{1}-\Delta_{1}+p_{11} \Delta_{1}\right)-\lambda_{2}
$$




$$
\begin{gathered}
\frac{\partial L_{2}}{\partial a_{22}}=0=\frac{\left(1-p_{22}\right)}{a_{2 \bullet}} \pi_{2}+p_{22} \frac{\left(1-p_{22}\right)}{a_{2 \bullet}} \Delta_{2}-\lambda_{2}=\frac{\left(1-p_{22}\right)}{a_{2} \bullet}\left(\pi_{2}+p_{22} \Delta_{2}\right)-\lambda_{2} \\
\frac{\partial L_{2}}{\partial \lambda_{2}}=0=a_{12}+a_{22}-N_{2} .
\end{gathered}
$$

Before presenting the solution to the VFP, we provide the following lemma. In what follows, we let $r_{i}=\frac{\Delta_{i}}{k_{i j}}$ and $\pi_{i}\left(z_{i}\right)=k_{i j}+z_{i} \Delta_{i}$.

Lemma 1 Let $k_{i j}>0$ for $i \neq j$, and let $r_{i} \in(-1,1]$. For any $\alpha \in[0,1]$ there exists a unique set of values $z_{1}^{*}, z_{2}^{*}, \Theta^{*} \in[0,1]$ that simultaneously satisfy

$$
\begin{gathered}
\text { (i) } 1-z_{1}=\Theta \frac{1+r_{1} z_{1}}{1+2 r_{1} z_{1}} \\
\text { (ii) } 1-z_{2}=(1-\Theta) \frac{1+r_{2} z_{2}}{1+2 r_{2} z_{2}} \\
\left(\text { iii } z_{1} \pi_{1}\left(z_{1}\right)+\left(1-z_{2}\right) \pi_{2}\left(z_{2}\right)=\alpha\left[\pi_{1}\left(z_{1}\right)+\pi_{2}\left(z_{2}\right)\right] .\right.
\end{gathered}
$$

Proof. See Appendix.

Theorem 1 Let $k_{i j}>0$ for $i \neq j$, and let $r_{i} \in(-1,1]$. Let $z_{1}^{*}, z_{2}^{*}$ and $\Theta^{*}$ be the solutions to the equations of Lemma 1 corresponding to $\alpha=\frac{N_{1}}{N}$. The unique solution to equations $(1)-(6)$, i.e., the Nash equilibrium of the VFP for $i, j=1,2$ and $j \neq i$, is

$$
a_{i i}^{*}=K^{-1} z_{i}^{*} \pi_{i}\left(z_{i}^{*}\right), a_{i j}^{*}=K^{-1}\left(1-z_{i}^{*}\right) \pi_{i}\left(z_{i}^{*}\right), \lambda_{1}=K \Theta^{*}, \lambda_{2}=K\left(1-\Theta^{*}\right)
$$

where $K=\frac{\pi_{1}\left(z_{1}^{*}\right)+\pi_{2}\left(z_{2}^{*}\right)}{N}$.

Proof. See Appendix.

It is useful to highlight a result established in the proof of Theorem 1 signifying the proportion of each firm owned by each fund. We do this in the next corollary. In what follows, an asterisk above any function denotes that function evaluated at the solution to the VFP presented in Theorem 1. 
Corollary 1 The solution to the VFP yields $p_{i i}^{*}=z_{i}^{*}$.

Interpreting $\frac{\pi_{i}^{*}}{a_{i \bullet}^{*}}$ as the resulting value per voucher in firm $i$, Theorem 1 establishes that these values are the same for both firms at the Nash equilibrium of the bidding game. Furthermore, this common value is equal to the economy-wide value of a voucher given by $\frac{\pi_{1}^{*}+\pi_{2}^{*}}{N}$. This common value of a voucher is also equal to the sum of the two shadow prices which is denoted by $K$ in Theorem 1 . An additional voucher to the system, yielding approximately the value $K$, would be divided between $F_{1}$ and $F_{2}$ in the amounts $\lambda_{1}$ and $\lambda_{2}$. Thus, $F_{1}$ would receive $\Theta^{*}$ percent of this additional amount, and $F_{2}$ the remainder, $1-\Theta^{*}$ where $\Theta^{*}$ incorporates, among other things, the relative skill levels of $F_{1}$ and $F_{2}$.

At the Nash equilibrium, a total of $K^{-1} \pi_{j}^{*}=N \frac{\pi_{j}^{*}}{\pi_{1}^{*}+\pi_{2}^{*}}$ vouchers are invested in firm $j$, $j=1,2$, with $F_{j}$ contributing $z_{j}^{*}$ percent of these vouchers. We can interpret this total either as the part of the outstanding number of vouchers acquired by firm $j$ being proportional to $\pi_{j}^{*}$, or as the profit of firm $j$ denominated in units of economy-wide value per voucher. Although the voucher investment in firm $j$ depends on $\pi_{j}^{*}$, this profit cannot be known in advance since it depends on the composition of ownership resulting from the bidding game itself. Finally, the ratio $\frac{a_{i i}^{*}}{a_{i j}^{*}}=\frac{p_{i i}^{*}}{p_{i j}^{*}}=\frac{z_{i}^{*}}{1-z_{i}^{*}}, j \neq i$, depends on all the parameters of the problem including the skill levels of the $F_{j}$. (Both Lemma 1 and Theorem 1 are generalizations of results that are found in Katz and Owen (1997).)

We next establish the revenue that $F_{j}$ receives as a consequence of the solution to the VFP. Let $\Pi^{*}=\pi_{1}^{*}+\pi_{2}^{*}$.

Corollary 2 At the Nash equilibrium of the VFP, the revenue to $F_{j}$ is equal to $\frac{N_{j}}{N} \Pi^{*}$.

Proof. See Appendix.

The solution to the VFP yields each $F_{j}$ the proportion $\frac{N_{j}}{N}$ of the sum of the profits produced by firms 1 and 2 at the Nash solution. This establishes that $R_{j}\left(N_{1}\right)=\frac{N_{j}}{N} \Pi^{*}$ and that profit 
equals $\delta_{j} \frac{N_{j}}{N} \Pi^{*}$. It also follows that at the Nash equilibrium, the revenue per voucher for each of the $F_{j}$ is identical. We can now return to the problem facing the $I_{l}$, the original voucher holders.

\section{The Voucher Investment Problem}

For the voucher investment problem (VIP) in which $I_{l}$ wishes to maximize $m_{l}, I_{l}$ must know $R_{1}(x+y)$ and $R_{2}(x+y)$. From Corollary 2 and the remarks following it, $R_{j}=p_{1 j}^{*} \pi_{1}^{*}+p_{2 j}^{*} \pi_{2}^{*}=$ $\frac{N_{j}}{N} \Pi^{*}$ where $\Pi^{*}=\pi_{1}^{*}+\pi_{2}^{*}$. Having assumed that each $I_{l}$ has the same information concerning the bidding game played by $F_{1}$ and $F_{2}$ conditional on the funds having received $N_{1}=x+y$ vouchers, and $N_{2}=N-N_{1}$ vouchers, respectively, it follows that each $I_{l}$ also knows the Nash

equilibrium of the VFP as presented in Theorem 1. Consequently, the respective objective functions of the $I_{l}$ can be restated as

$$
m_{1}(x, y)=\frac{x}{x+y} \delta_{1} \frac{N_{1}}{N} \Pi^{*}+\frac{V_{1}-x}{\left(V_{1}-x\right)+\left(V_{2}-y\right)} \delta_{2} \frac{N_{2}}{N} \Pi^{*}
$$

and

$$
m_{2}(x, y)=\frac{y}{x+y} \delta_{1} \frac{N_{1}}{N} \Pi^{*}+\frac{V_{2}-y}{\left(V_{1}-x\right)+\left(V_{2}-y\right)} \delta_{2} \frac{N_{2}}{N} \Pi^{*}
$$

Since $N_{1}=x+y$ and $N_{2}=N-N_{1}$, the last expressions can be reduced to

$$
m_{1}(x, y)=\left[\delta_{1} \frac{x}{N}+\delta_{2} \frac{V_{1}-x}{N}\right] \Pi^{*}(x+y)
$$

and

$$
m_{2}(x, y)=\left[\delta_{1} \frac{y}{N}+\delta_{2} \frac{V_{2}-y}{N}\right] \Pi^{*}(x+y)
$$

Thus, in the voucher investment problem (VIP), investor $I_{1}$ seeks $x^{*}$ where

$$
x^{*}=\arg \max _{x \in\left[0, V_{1}\right]} m_{1}(x, y) \text { subject to } y \in\left[0, V_{2}\right]
$$


and investor $I_{2}$ seeks $y^{*}$ where

$$
y^{*}=\arg \max _{y \in\left[0, V_{2}\right]} m_{2}(x, y) \text { subject to } x \in\left[0, V_{1}\right]
$$

We next define an efficient allocation of vouchers. Let $N_{1}^{*}=\arg \max _{N_{1} \in[0, N]} \Pi^{*}\left(N_{1}\right)$. Note that $N_{1}^{*}$ is an apportionment of vouchers to the VPFs that achieves the maximum total profit.

Definition 1 An allocation of vouchers $(x, y), x \in\left[0, V_{1}\right], y \in\left[0, V_{2}\right]$, is an efficient allocation if $x+y=N_{1}^{*}$.

\subsection{The case when $\delta_{1}=\delta_{2}=\delta$}

We continue by investigating the case in which the $F_{j}$ pay out the same proportion of their revenues to the $I_{l}$; that is the case when $\delta_{1}=\delta_{2}=\delta$. In this situation, $m_{l}=\delta \frac{V_{l}}{N} \Pi^{*}(x+y)$. Since increasing $\Pi^{*}(x+y)$ benefits both $I_{l}$, it is in their joint interest to achieve the largest possible $\Pi^{*}$ by their respective voucher investments. It follows that it is in the interest of the $I_{l}$ to choose their voucher investments $x^{*}$ and $y^{*}$, respectively, such that $x^{*}+y^{*}=N_{1}^{*}$, i.e., to choose their investments to be efficient. It also follows that there exists an infinity of equilibria to the VIP of the form $\left(x^{*}, y^{*}\right)$ where $x^{*}=N_{1}^{*}-y^{*}$ for $x^{*} \in\left[0, V_{1}\right]$ and for $y^{*} \in\left[0, V_{2}\right] .{ }^{23}$ We summarize the previous remarks in the following theorem.

Theorem 2 When $\delta_{1}=\delta_{2}=\delta$, there exists an infinity of equilibria to the VIP consisting of the set of efficient allocations.

But despite the fact that the $I_{l}$ find it in their interest to have $x^{*}+y^{*}=N_{1}^{*}$, the noncooperative nature of the Nash game offers no mechanism to cause the target $N_{1}^{*}$ to be met. ${ }^{24}$

\footnotetext{
${ }^{23}$ Note that the VIP is similar in structure to the game of "Divide the Dollars" which has an infinite number of Nash equilibria. See, for example, Myerson (1991).

${ }^{24}$ Of course, efficiency follows if and only if either $I_{l}$ ends up with all the vouchers, i.e., $\frac{V_{l}}{N}=1$.
} 
Since the target represents the division of the total number of vouchers in the system between the $F_{j}$ that maximizes economy-wide profit, there is consequently no mechanism to achieve this efficient outcome. ${ }^{25}$ Thus, the failure to achieve efficiency is the result of the absence of coordination between the voucher holders.

Notice that this coordination failure is present even in the case in which the voucher holders have identical and full information, and have as their goal the wish to allocate their vouchers in a manner consistent with the maximization of economy-wide profit. We now show that the introduction of uncertainty exacerbates the situation since it creates a situation in which the goal of the voucher holders is no longer one of maximizing total economy-wide profit; in fact, we show that the goal differs for the different voucher holders.

When uncertainty is present, we must consider the investors' attitudes toward risk. To this end, we let $u_{l}: \Re_{+} \rightarrow \Re_{+}$with $u_{l}\left(m_{l}\right)=1-\exp \left(-\gamma_{l} m_{l}\right), \gamma_{l}>0$, be the utility function of $I_{l}$. We assume that all information is known to the voucher holders as before, with one exception: $\Delta_{1}$ is known imperfectly. We assume that both voucher holders perceive $\widetilde{\Delta_{1}}$ as a random variable, distributed normally with mean $\Delta_{1}$ (as before) and variance $\sigma^{2}$. We denote this density as $\phi\left(\Delta_{1}, \sigma^{2}\right)$. It follows that $\widetilde{\Pi^{*}}$ is random since $\widetilde{\Pi^{*}}=k_{12}+k_{21}+p_{11} \widetilde{\Delta_{1}}+p_{22} \Delta_{2}$. The expectation of any function of $\widetilde{\Delta_{1}}$ with respect to $\phi$ is denoted by $E_{\phi}$. Thus $E_{\phi} \widetilde{\Pi^{*}}=\Pi^{*}$ with $\Pi^{*}$ as before. Let $N_{1}^{*}(\phi)=\max _{N_{1}} E_{\phi} \Pi^{*}=\max _{N_{1}} \Pi^{*}\left(N_{1}\right)$. We define Assumption A to be made up of the following statements:

(i) $I_{l}$ has utility function $u_{l}\left(m_{l}\right)=1-\exp \left(-\gamma_{l} m_{l}\right), \gamma_{l}>0$,

(ii) $I_{l}$ is a von Neumann-Morgenstern expected utility of wealth maximizer,

(iii) $\delta_{1}=\delta_{2}=\delta$,

(iv) $\widetilde{\Delta_{1}}$ is distributed as $\phi\left(\Delta_{1}, \sigma^{2}\right)$,

\footnotetext{
${ }^{25}$ Although there are focal equilibria that eliminate this coordination failure, there are no self-enforcing mechanisms to bring them about.
} 
(v) All other information is known with certainty,

(vi) Both $I_{l}$ have the same information,

(vii) The funds $F_{j}$ bid using $E_{\phi} \widetilde{\Delta_{1}}$ as input to their decisions.

In what follows, we let $N_{11}$ be the target of $I_{1}$ and $N_{12}$ be the target of $I_{2}$.

Theorem 3 Let Assumption $A$ hold. Let $\gamma_{1} V_{1} \neq \gamma_{2} V_{2}, \Delta_{1}>0$ and $N_{1}^{*}(\phi) \in(0, N)$. Then there exists a constant $c$ such that for $\sigma^{2} \in(0, c), N_{11} \neq N_{12}, N_{11}<N_{1}^{*}(\phi)$, and $N_{12}<N_{1}^{*}(\phi)$.

Proof. See Appendix.

Thus, the immediate impact of the introduction of uncertainty regarding the skills of $F_{1}$ causes a shifting of vouchers away from $F_{1}$. As a consequence, even if $N_{1}^{*}(\phi)$ were close to $N$, $F_{2}$ would receive more vouchers as the uncertainty increases. Earlier we showed that when $\delta_{1}=\delta_{2}$ and when all information was known with certainty, each $I_{l}$ strove to achieve the target $N_{1}^{*}$, which, if achieved, would maximize the voucher holders' respective wealths as well as implement the efficient outcome. That is, the voucher holders were aiming at the right target. When uncertainty is introduced into the model, we see that the target at which the $I_{l}$ aim need not be $N_{1}^{*}(\phi)$ and, in fact, need not even be the same.

\subsection{The case when $\delta_{1} \neq \delta_{2}$}

We have assumed so far that the $F_{j}$ have identical cost structures. Generally, however, since the $F_{j}$ are not identical, they could have different cost structures, leading them to select different percentages of their revenues to pay out, that is, $\delta_{1} \neq \delta_{2}$. When $\delta_{1} \neq \delta_{2}$, it is no longer true that the $I_{l}$ will both benefit by seeking to maximize $\Pi^{*}$ since the share of $\Pi^{*}$ that $I_{l}$ receives depends, in this case, on the investments $x^{*}$ and $y^{*}$. Importantly, for the case $\delta_{1} \neq \delta_{2}$, the optimal choices of $x^{*}$ and $y^{*}$ by $I_{1}$ and $I_{2}$, respectively, need not always produce a division of the vouchers consistent with the maximization of economy-wide profit. We show 
these results to be true in Theorem 4 , where we present the solution to the VIP when $\delta_{1} \neq \delta_{2}$. To make our point as starkly as possible, we let $V_{1}=V_{2}$.

Theorem 4 Let $\delta_{1} \neq \delta_{2}, V_{1}=V_{2}=V$, and let $G\left(N_{1}\right)=\Pi^{*}\left(N_{1}\right)+\frac{N}{2}\left(\frac{N_{1}}{N}+\frac{\delta_{2}}{\delta_{1}-\delta_{2}}\right) \frac{d \Pi^{*}\left(N_{1}\right)}{d N_{1}}$ for $N_{1} \in(0, N)$.

a.) Then the Nash equilibrium of the VIP is

$$
x^{*}=y^{*}=\frac{N_{1}^{\circ}}{2}
$$

where either $N_{1}^{\circ} \in(0, N)$ and satisfies $G\left(N_{1}^{\circ}\right)=0$, or $N_{1}^{\circ}=0$ or $N$.

b.) If $\Delta_{j} \neq 0$ for at least one value of $j$ and $N_{1}^{\circ} \in(0, N)$, then $N_{1}^{\circ} \neq N_{1}^{*}$.

Proof. See Appendix.

When payouts are different, each $I_{l}$ will invest $\frac{N_{1}^{\circ}}{2}$ in $F_{1}$ yielding a total of $N_{1}^{\circ}$ vouchers to $F_{1}$. Since $N_{1}^{\circ} \neq N_{1}^{*}, N_{1}^{\circ}$ will not be the efficient allocation of vouchers to $F_{1}$, and thus will not maximize total economy-wide profit. Additionally, whereas a coordination failure between the $I_{l}$ is responsible for inefficient outcomes when $\delta_{1}=\delta_{2}$, even permitting coordination when $\delta_{1} \neq \delta_{2}$ would not result in an efficient outcome. That is, when $\delta_{1} \neq \delta_{2}$, the goal of the voucher holders is not the goal of maximizing total economy-wide profit, as it was for the case when $\delta_{1}=\delta_{2}$.

\section{Discussion and Conclusions}

Economies in transition have experimented with the use of vouchers to transfer assets from state to private ownership. While the widespread distribution of vouchers had an appeal on equity grounds, the risk was that the resulting ownership structure would be so widely dispersed as to impede the development of effective corporate governance, thereby limiting the improvement attainable in economic performance. Voluntarily, and somewhat serendipitously, 
VPFs emerged as a common feature of the mass privatization programs employing vouchers. Moreover, voucher privatization funds became the dominant players in the voucher auctions, having gathered most of the vouchers from the individual voucher holders. As the dominant players, they offered a means through which the problems associated with widespread ownership might be tempered. By exchanging their own shares for the vouchers of the original individual voucher recipients, VPFs were able to concentrate their bidding power and subsequently their ownership. The degree to which they were able to acquire stakes of sufficient size to provide them with the necessary incentives to monitor and restructure the firms in their portfolios is an empirical question.

Neglected in most of the discussions of voucher privatization, however, is the role played by the voucher endowment to which each VPF was subjected. As we noted earlier, regardless of the potential skill of a VPF, unless it attracted vouchers, it could not bid in the voucher auctions. Our work emphasizes the importance of the decisions that lead to the initial distribution of vouchers among the VPFs, and shows that there is no mechanism that guarantees that the distribution of vouchers between funds of different skill levels will be such that the profits of the firms in which they acquire shares will be maximized. It follows that we have shown that the initial conditions of voucher privatizations are flawed.

In this paper we investigated the implications of voucher privatization and found that its two purposes, equity and efficient economic performance, were in conflict. We showed that a coordination failure occurs in the simplest of frameworks, when voucher holders have identical and full information and when the payouts of the VPFs are identical. ${ }^{26}$ In these cases, the voucher holders wished to allocate their vouchers between the funds in a manner that coincided with the allocation that would induce the economy-wide efficient outcome; however, given the

\footnotetext{
${ }^{26}$ This echos an earlier finding of a coordination failure by Laban and Wolf (1993) in which the possibility of a coordination failure leads to an underprivatization trap.
} 
multiple equilibria to the Nash game, the voucher holders were unable to coordinate their efforts and thus could not implement the economy-wide efficient solution. Consequently, even if the VPFs used the vouchers they obtained to bid and acquire shares in the underlying firms in an optimal manner, the earlier coordination failure among the voucher holders would prevent the VPFs from obtaining the optimal endowment of vouchers, thus precluding the efficient outcome.

When uncertainty regarding the skills of the funds was incorporated into the model, the voucher holders no longer agreed on the desired allocation of vouchers to the funds; moreover, the allocations that were desired by the voucher holders were not consistent with the efficient one. When payouts of the funds differed, the interests of the voucher holders were inconsistent with the maximization of economy-wide profit. Thus, even if it were possible for the voucher holders to coordinate their choices, the presence of either uncertainty or differing payouts prevents an efficient outcome for voucher privatization.

There are plausible reasons for assuming that payouts might differ: the funds could have different cost structures or the funds could announce payouts unrelated to their cost structures merely to attract vouchers. Also, there is nothing in the structure of the one-shot nature of the voucher privatization process that would lead to a common payout ratio. In the Czech Republic, and also in Russia, VPFs attempted to attract voucher investment by advertising. Not only did the cost of advertising vary across funds, but also the promised payouts differed widely.

There are also particular reasons for assuming investor uncertainty in the case of economies in transition; specifically, the VPFs and privatized firms were new and had no track-records. Both the Czech and the Russian plans, for example, permitted easy entry into the relatively unregulated markets for VPFs. These newly created VPFs had no prior histories and, there- 
fore, the voucher holders had to be uncertain regarding the skills of the funds. Given this environment, our model predicts that voucher privatization will not succeed in maximizing economy-wide profit.

As we have shown, it was the bidding process at the auctions in which the VPFs were the dominant players that determined the pattern of ownership of the firms offered for voucher privatization. In the Polish mutual fund approach, however, these choices were part of the design of the plan. To the degree that the government was able to choose a group of comparably skilled funds, the Polish plan had the potential to achieve both its equity and efficiency goals. ${ }^{27}$ Critically, by having the government choose the NIFs and the design of the selection process by which they acquired firms, the Polish plan avoided the coordination failure that is inherent in voucher privatization. Although the Polish plan avoided the pitfall of a coordination failure, it did so at the expense of postponing individual participation in investment decision-making. Observing the economic performances of the Czech Republic and Poland some ten years into the transition, it is hard not to conclude that the early promise of voucher privatization was misplaced, and that the delay in individual participation in investment decisions was the wiser choice.

Still, the question of the actual longer term impact of VPFs on corporate governance is an empirical one and outside the scope of our analysis. We note, however, that the belief that problems in the original voucher privatization process might easily be rectified by trades in the secondary market seems not to be justified.

\footnotetext{
${ }^{27}$ Note that the ability of a government to recognize a method by which efficiency might be improved does not mean that the government has the ability to improve efficiency. The Polish government acknowledged as much by calling upon the expertise of Western investment banks to participate in the management of the NIFs.
} 


\section{References}

$\natural$ This paper is a revised version of a paper originally titled "The Investment Choices of Voucher Holders and their Impact on Privatized Firm Performance," ESSEC Working Paper DR96020 and New York University, Stern School of Business Working Paper EC-96-08. It also was once titled "The Impact of Voucher Privatization on Efficiency." The original version was written while we were Visiting Professors at ESSEC, Cergy, France, and we wish to thank ESSEC for its hospitality. We benefitted from the comments of Patricia Charlety, Irena Grosfeld, Roy Radner, Holger Wolf, Radu Vranceanu and the participants of the Finance-Economics seminar at ESSEC, the Economics seminar at CERGE-EI (Prague), the Industrial Organization seminar at NYU, the Economics seminar at the New Economic School, Moscow, Russian Federation, and the anonymous referees and The Editor of this journal.

Boycko, M., Shleifer, A. and Vishny, R. (1994). "Voucher Privatization," Journal of Financial Economics 35, pp.249-266.

Boycko, M., Shleifer, A., and Vishny, R. (1995). Privatizing Russia. Cambridge, Mass.: The MIT Press.

Coffee, J. (1996). "Investment Privatization Funds: The Czech Experience," in Frydman, R., C. Gray, and A. Rapaczynski (eds.), Corporate Governance in Central Europe and Russia, Volume 1: Banks, Funds, and Foreign Investors, Budapest: Central European University Press.

Claessens, S. and Djankov, S. (1999). "Ownership Concentration and Corporate Performance in the Czech Republic," Journal of Comparative Economics 27, pp. 498513. 
Frydman, R., Rapaczynski, A. and Earle, J., et al. (1993). The Privatization Process in Central Europe. New York: Central European University Privatization Reports, volume 1, CEU Press.

Frydman, R., Pistor, K. and Rapaczynski, A. (1996). "Investing in InsiderDominated Firms: A Study of Russian Voucher Privatization Funds," Frydman, R., C. Gray, and A. Rapaczynski (eds.), Corporate Governance in Central Europe and Russia, Volume 1: Banks, Funds, and Foreign Investors, Budapest: Central European University Press.

Grosfeld, I. (1996). "Financial Systems in Transition: The Role of Banks in Corporate Governance," DELTA, CNRS, mimeo.

Hingorani, A., Lehn, K., and Makhija, A. (1997). "Investor behavior in mass privatization: The case of the Czech voucher scheme." Journal of Financial Economics 44, pp. 349-396.

Katz, B. and Owen, J. (1997). "Optimal Voucher Privatization Fund Bids When Bidding Affects Firm Performance." Journal of Comparative Economics 24, no. 1, pp. 25-43.

Laban, R. and Wolf, H. (1993). "Large Scale Privatization in Transition Economies," American Economic Review 85, no.5, pp. 1119-1210.

Megginson, W. and Netter, J. (2000). "From State to Market: A Survey of Empirical Studies on Privatization, mimeo

Myerson, R. (1991). Game Theory: Analysis of Conflict. Cambridge, Mass.: Harvard University Press. 
Sachs, J. (1993). Poland's Jump to the Market Economy. Cambridge, Mass.: The MIT Press.

Stiglitz, J. (1999). "Whither Reform? Ten Years of the Transition," World Bank Annual Bank Conference on Development Economics, April 28-30, 1999.

Van Wijnbergen S. and Marcincin, A. (1995). "Voucher Privatization, Corporate Control and the Cost of Capital: An Analysis of the Czech Privatization Programme," Centre for Economic Policy Research Discussion Paper, Series No. 1215, London.

Weiss, A. and Nikitin, G. (1999). "Effects of Ownership by Investment Funds on the Performance of Czech Firms," mimeo; forthcoming in Meyendorff, A. (ed.) Financial systems in Transition: The Design of Financial Systems in Central Europe, MIT Press.

\section{Appendix}

\subsection{Proof of Lemma 1}

The value $z_{1}^{*}$ is determined by equation $(i)$. Multiplying this equation through by the denominator of the right hand side and collecting terms, it follows that $z_{1}^{*}$ must satisfy $2 r_{1} z_{1}^{2}-z_{1}\left[(2-\Theta) r_{1}-1\right]-(1-\Theta)=0$ for a given $\Theta$. This convex polynomial (or concave polynomial depending on the sign of $\left.r_{1}\right)$ equals $-(1-\Theta)$ when $z_{1}=0$ and $\Theta\left(1+r_{1}\right)$ when $z_{1}=1$. Since $r_{1} \in(-1,1]$, we have that $z_{1}^{*} \in[0,1]$ and is unique in this interval for any $\Theta \in[0,1]$. The unique value of $z_{2}^{*} \in[0,1]$ is established by a similar argument applied to equation (ii). We next show that equation (iii) is satisfied for $\Theta^{*} \in[0,1]$.

Since the $z_{i}$ depend on $\Theta$, we define $B(\Theta)=z_{1} \pi_{1}\left(z_{1}\right)+\left(1-z_{2}\right) \pi_{2}\left(z_{2}\right)-\alpha\left[\pi_{1}\left(z_{1}\right)+\pi_{2}\left(z_{2}\right)\right]$. To prove the uniqueness of $\Theta^{*}$ we show that $B(0) \geq 0, B(1) \leq 0$ with at least one of these inequalities strict, and $\frac{d B(\Theta)}{d \Theta}<0$ for $\Theta \in(0,1)$. When $\Theta=0$, equations $(i)$ and (ii) yield 
$z_{1}=\left(1-z_{2}\right)=1$ and therefore $B(0)=(1-\alpha)\left[\pi_{1}(1)+\pi_{2}(0)\right]$. Since $\pi_{i}\left(z_{i}\right)=k_{i j}\left[1+z_{i} r_{i}\right]$ and $r_{i} \in(-1,1]$, it follows that $\pi_{i}\left(z_{i}\right)>0$ and that $B(0) \geq 0$ with $B(0)=0$ only if $\alpha=1$. When $\Theta=1$, equations $(i)$ and $(i i)$ yield $z_{1}=\left(1-z_{2}\right)=0$ and thus $B(1)=-\alpha\left[\pi_{1}(0)+\pi_{2}(1)\right]$. Therefore, $B(1) \leq 0$ and $B(1)=0$ only if $\alpha=0$. It then also follows that at least one of the inequalities involving $B(0)$ and $B(1)$ must be strict.

Differentiating with respect to $\Theta$, we have $\frac{d B(\Theta)}{d \Theta}=\frac{d z_{1}}{d \Theta}\left[k_{12}+2 z_{1} \Delta_{1}-\alpha \Delta_{1}\right]-\frac{d z_{2}}{d \Theta}\left[k_{21}+2 z_{2} \Delta_{2}-\right.$ $\left.(1-\alpha) \Delta_{2}\right]$. When $\Delta_{1} \geq 0, k_{12}+2 z_{1} \Delta_{1}-\alpha \Delta_{1} \geq k_{12}-\Delta_{1}=k_{12}\left(1-r_{1}\right)>0$ by assumption. When $\Delta_{1}<0, k_{12}+2 z_{1} \Delta_{1}-\alpha \Delta_{1} \geq k_{12}+2 z_{1} \Delta_{1}=k_{12}\left(1+2 z_{1} r_{1}\right)$. Rearranging terms in equation (i) we see that $1+2 z_{1} r_{1}>0$ for $\Theta \in(0,1)$. Therefore, the coefficient of $\frac{d z_{1}}{d \Theta}$ is positive for all $\Delta_{1}$ when $\Theta \in(0,1)$. Similarly, the coefficient of $-\frac{d z_{2}}{d \Theta}$ is positive for $\Theta \in(0,1)$. To determine the signs of these derivatives, we solve for $z_{i}$ explicitly in terms of $\Theta$ and differentiate. Thus, $z_{1}=\frac{1}{4 r_{1}}\left\{(2-\Theta) r_{1}-1+\left[D_{1}(\Theta)\right]^{\frac{1}{2}}\right\}$ where $D_{1}(\Theta)=\left[(2-\Theta) r_{1}-1\right]^{2}+8 r_{1}(1-\Theta)$. Differentiating and collecting terms we have $\frac{d z_{1}}{d \Theta}=-\frac{1}{4}\left\{1+\left[(2-\Theta) r_{1}+3\right]\left[D_{1}(\Theta)\right]^{-\frac{1}{2}}\right\}$. Therefore, $\frac{d z_{1}}{d \Theta}<0$ for $\Theta \in[0,1]$ and $r_{1} \in(-1,1]$. Also, $z_{2}=\frac{1}{4 r_{2}}\left\{(1+\Theta) r_{2}-1+\left[D_{2}(\Theta)\right]^{\frac{1}{2}}\right\}$ where $D_{2}(\Theta)=\left[(1+\Theta) r_{2}-1\right]^{2}+8 r_{2} \Theta$. It follows that $\frac{d z_{2}}{d \Theta}=\frac{1}{4}\left\{1+\left[(1+\Theta) r_{2}+3\right]\left[D_{2}(\Theta)\right]^{-\frac{1}{2}}\right\}$ and thus $\frac{d z_{2}}{d \Theta}>0$ for $\Theta \in[0,1]$ and $r_{2} \in(-1,1]$. We can now conclude that $\frac{d B(\Theta)}{d \Theta}<0$ for $\Theta \in(0,1)$ and $r_{i} \in(-1,1]$.

\subsection{Proof of Theorem 1}

The first-order conditions of equation (1) - (6) can be replaced by the following equivalent six equations:

$$
\lambda_{1}+\lambda_{2}=\frac{\pi_{1}\left(p_{11}\right)}{a_{1}}
$$




$$
\begin{gathered}
\lambda_{1}+\lambda_{2}=\frac{\pi_{2}\left(p_{22}\right)}{a_{2} \bullet} \\
\lambda_{1}+\lambda_{2}=\frac{\pi_{1}\left(p_{11}\right)+\pi_{2}\left(p_{22}\right)}{N} \\
\left(1-p_{11}\right)=\frac{\lambda_{1} a_{1} \bullet}{\pi_{1}\left(p_{11}\right)+p_{11} \Delta_{1}} \\
\left(1-p_{22}\right)=\frac{\lambda_{2} a_{2} \bullet}{\pi_{2}\left(p_{22}\right)+p_{22} \Delta_{2}} \\
N_{1}=a_{1} \bullet p_{11}+a_{2} \bullet\left(1-p_{22}\right) .
\end{gathered}
$$

The relationship between the two sets of equations is established as follows. Equations $\left(4^{\prime}\right)$ and $\left(5^{\prime}\right)$ are just equations (1) and (5). Equation $\left(1^{\prime}\right)$ results from summing equations (1) and (4). Equation $\left(2^{\prime}\right)$ results from summing equations (2) and (5). Equation $\left(6^{\prime}\right)$ is equation (3) rewritten using the definition that $a_{i j}=a_{i \bullet} p_{i j}$ and that $p_{21}=\left(1-p_{22}\right)$. Finally, equation $\left(3^{\prime}\right)$ results from summing equations (3) and (6) and imposing the requirement that $N_{1}+N_{2}=N$.

Solving for $a_{i \bullet}$ in equations $\left(1^{\prime}\right)$ and $\left(2^{\prime}\right)$ and substituting these values in equations $\left(4^{\prime}\right)$ through $\left(6^{\prime}\right)$, and replacing $\lambda_{1}+\lambda_{2}$ using equation $\left(3^{\prime}\right)$, yields

$$
\begin{gathered}
\left(1-p_{11}\right)=\frac{\Theta \pi_{1}\left(p_{11}\right)}{\pi_{1}\left(p_{11}\right)+p_{11} \Delta_{1}} \\
\left(1-p_{22}\right)=\frac{(1-\Theta) \pi_{2}\left(p_{22}\right)}{\pi_{2}\left(p_{22}\right)+p_{22} \Delta_{2}} \\
N_{1}=N \frac{p_{11} \pi_{1}\left(p_{11}\right)+\left(1-p_{22}\right) \pi_{2}\left(p_{22}\right)}{\pi_{1}\left(p_{11}\right)+\pi_{2}\left(p_{22}\right)}
\end{gathered}
$$


where $\Theta=\frac{\lambda_{1}}{\lambda_{1}+\lambda_{2}}$. Since $\pi_{i}\left(p_{i i}\right)=k_{i j}+p_{i i} \Delta_{i}$, we can divide the numerators and denominators of the right-hand-sides of equations $\left(4^{\prime}\right)$ and $\left(5^{\prime}\right)$ by $k_{i j}$ and call $p_{i i}=z_{i}$. With these changes, equations $\left(4^{\prime}\right)-\left(6^{\prime}\right)$ become the equations of Lemma 1 with $\alpha=\frac{N_{1}}{N}$. It follows from this lemma that there is a unique solution $p_{i i}^{*}=z_{i}^{*}, i=1,2$, and $\Theta^{*}$ all in the unit interval satisfying these equations. Since the $p_{i i}^{*}$ determine the $\pi_{i}\left(p_{i i}^{*}\right)$, it follows from $\left(3^{\prime}\right)$ that $\lambda_{1}+\lambda_{2}=\frac{\pi_{1}\left(z_{1}^{*}\right)+\pi_{2}\left(z_{2}^{*}\right)}{N}=$ $K$. Since $a_{i i}^{*}=a_{i \bullet}^{*} p_{i i}^{*},\left(1^{\prime}\right)$ and $\left(2^{\prime}\right)$ yield $a_{i i}^{*}=K^{-1} z_{i}^{*} \pi_{i}\left(z_{i}^{*}\right)$. The values of $a_{i j}, j \neq i$, follow by subtraction. Finally, $\lambda_{1}=\left(\lambda_{1}+\lambda_{2}\right) \frac{\lambda_{1}}{\lambda_{1}+\lambda_{2}}=K \Theta^{*}$ with $\lambda_{2}$ also following by subtraction.

This unique solution maximizes the respective Lagrangians since, when $r_{i} \in(-1,1]$, the Hessian of each Lagrangian is strictly negative, i.e., the Lagrangians are strictly concave functions.

\subsection{Proof of Corollary 2}

The revenue to $F_{j}$ at the Nash equilibrium of the VFP is $p_{1 j}^{*} \pi_{1}^{*}+p_{2 j}^{*} \pi_{2}^{*}$. Using Corollary 1 and the fact that $p_{i 1}+p_{i 2}=1$, we have that the revenue to $F_{1}$ is $z_{1}^{*} \pi_{1}^{*}+\left(1-z_{2}^{*}\right) \pi_{2}^{*}$. This in turn must

equal $\frac{N_{1}}{N}\left(\pi_{1}^{*}+\pi_{2}^{*}\right)$ by the determination of $\Theta^{*}$ of Theorem 1 . Thus the revenue for $F_{1}$ is $\frac{N_{1}}{N} \Pi^{*}$. Since the revenue for $F_{2}$ is $\left(1-z_{1}^{*}\right) \pi_{1}^{*}+z_{2}^{*} \pi_{2}^{*}=\pi_{1}^{*}+\pi_{2}^{*}-\left[z_{1}^{*} \pi_{1}^{*}+\left(1-z_{2}^{*}\right) \pi_{2}^{*}\right]=\Pi^{*}\left(1-\frac{N_{1}}{N}\right)=\frac{N_{2}}{N} \Pi^{*}$ the result follows.

\subsection{Proof of Theorem 3}

We first establish the following lemma.

Lemma 2 Let $\Delta_{j} \neq 0$ for at least one value of $j$ and let $r_{i} \in(-1,1], i=1,2$. Then,

a. $\Pi^{*}\left(\Theta^{*}\right)$ is strictly concave for $\Theta^{*} \in(0,1)$

b. $\frac{d \Theta^{*}}{d N_{1}}<0$. 
Proof. a. In the proof of Lemma 1 (found in Appendix 8.1), we showed that $\frac{d z_{1}}{d \Theta}=$ $-\frac{1}{4}\left\{1+\left[(2-\Theta) r_{1}+3\right]\left[D_{1}(\Theta)\right]^{-\frac{1}{2}}\right\}$ and $\frac{d z_{2}}{d \Theta}=\frac{1}{4}\left\{1+\left[(1+\Theta) r_{2}+3\right]\left[D_{2}(\Theta)\right]^{-\frac{1}{2}}\right\}$ with $D_{i}(\Theta) \geq 0$. Differentiating these equations with respect to $\Theta$ yields $\frac{d^{2} z_{i}}{d \Theta^{2}}=-2 r_{i}\left(1+r_{i}\right)\left[D_{i}(\Theta)\right]^{-\frac{3}{2}}, i=1,2$. Since $\Pi^{*}=\pi_{1}^{*}+\pi_{2}^{*}=k_{12}+k_{21}+\Delta_{1} z_{1}^{*}+\Delta_{2} z_{2}^{*}$, we have $\frac{d^{2} \Pi^{*}}{d \Theta^{*^{2}}}=-2 \sum_{i=1}^{2} \Delta_{i} r_{i}\left(1+r_{i}\right)\left[D_{i}(\Theta)\right]^{-\frac{3}{2}}$. Since $\Delta_{j} \neq 0$ for some $j, \Delta_{i}$ and $r_{i}$ are of the same sign and $r_{i} \in(-1,1]$, we have $\frac{d^{2} \Pi^{*}}{d \Theta^{* 2}}<0$ and the result follows.

b. From Theorem $1, \Theta^{*}$ is determined to make $z_{1}^{*} \pi_{1}^{*}+\left(1-z_{2}^{*}\right) \pi_{2}^{*}=\frac{N_{1}}{N}\left(\pi_{1}^{*}+\pi_{2}^{*}\right)$. Implicit differentiation with respect to $N_{1}$ yields

$$
\begin{aligned}
& \left(\pi_{1}^{*}+z_{1}^{*} \Delta_{1}\right) \frac{d z_{1}^{*}}{d \Theta^{*}} \frac{d \Theta^{*}}{d N_{1}}+\left(-\pi_{2}^{*}+\left(1-z_{2}^{*}\right) \Delta_{2}\right) \frac{d z_{2}^{*}}{d \Theta^{*}} \frac{d \Theta^{*}}{d N_{1}} \\
= & \frac{1}{N}\left(\pi_{1}^{*}+\pi_{2}^{*}\right)+\frac{N_{1}}{N}\left(\Delta_{1} \frac{d z_{1}^{*}}{d \Theta^{*}} \frac{d \Theta^{*}}{d N_{1}}+\Delta_{2} \frac{d z_{2}^{*}}{d \Theta^{*}} \frac{d \Theta^{*}}{d N_{1}}\right) .
\end{aligned}
$$

It then follows that

$$
\left[\frac{d \Theta^{*}}{d N_{1}}\right]^{-1}=K^{-1}\left[\left(\pi_{1}^{*}+\left(z_{1}^{*}-\frac{N_{1}}{N}\right) \Delta_{1}\right) \frac{d z_{1}^{*}}{d \Theta^{*}}-\left(\pi_{2}^{*}+\left(z_{2}^{*}+\frac{N_{1}}{N}-1\right) \Delta_{2}\right) \frac{d z_{2}^{*}}{d \Theta^{*}}\right]
$$

As in the proof of Lemma 1, with $\alpha=\frac{N_{1}}{N}$, the expression in brackets is negative and $K$ is positive and the result follows.

\section{We now state the proof of Theorem 3.}

Since $\delta_{1}=\delta_{2}$ and $\widetilde{\Delta_{1}}$ is random, $\widetilde{m_{l}}=\delta \frac{V_{l}}{N} \widetilde{\Pi^{*}}(x+y)=\delta \frac{V_{l}}{N}\left[k_{12}+k_{21}+p_{11}^{*} \widetilde{\Delta_{1}}+p_{22}^{*} \Delta_{2}\right]$ where $p_{11}^{*}$ depends on $N_{1}=x+y$. Then $E_{\phi}\left(m_{l}\right)=\delta \frac{V_{l}}{N}\left[k_{12}+k_{21}+p_{11}^{*} \Delta_{1}+p_{22}^{*} \Delta_{2}\right]=\delta \frac{V_{l}}{N} \Pi^{*}(x+y)$ and $V\left(m_{l}\right)=E_{\phi}\left(m_{l}^{2}\right)-\left[E_{\phi}\left(m_{l}\right)\right]^{2}=\left[\delta \frac{V_{l}}{N} p_{11}^{*}\right]^{2} \sigma^{2}$. By the property of the moment-generating function of the normal distribution $E_{\phi}\left[u_{l}\left(m_{l}\right)\right]=1-E_{\phi}\left[\exp \left(-\gamma_{l} m_{l}\right)\right]=1-\exp \left[-\gamma_{l}\left(\delta \frac{V_{l}}{N}\right)\left(\Pi^{*}(x+y)-\right.\right.$ $\left.\left.\gamma_{l} \delta \frac{V_{l}}{2 N} p_{11}^{* 2} \sigma^{2}\right)\right]$. Maximizing expected utility is achieved by maximizing $\Pi^{*}(x+y)-\gamma_{l} \delta \frac{V_{l}}{2 N} p_{11}^{* 2} \sigma^{2}$. The conditions for an internal solution for the $I_{l}$ are respectively given by the first-order conditions

$$
\frac{d \Pi^{*}}{d \Theta^{*}} \frac{d \Theta^{*}}{d N_{1}} \frac{d N_{1}}{d x}-\frac{\delta \gamma_{1} V_{1} p_{11}^{*} \sigma^{2}}{N} \frac{d p_{11}^{*}}{d \Theta^{*}} \frac{d \Theta^{*}}{d N_{1}} \frac{d N_{1}}{d x}=0
$$


and

$$
\frac{d \Pi^{*}}{d \Theta^{*}} \frac{d \Theta^{*}}{d N_{1}} \frac{d N_{1}}{d y}-\frac{\delta \gamma_{2} V_{2} p_{11}^{*} \sigma^{2}}{N} \frac{d p_{11}^{*}}{d \Theta^{*}} \frac{d \Theta^{*}}{d N_{1}} \frac{d N_{1}}{d y}=0 .
$$

Since $\frac{\partial N_{1}}{\partial x}=\frac{\partial N_{1}}{\partial y}=1$ and for $\Theta^{*} \in[0,1], \frac{d \Theta^{*}}{d N_{1}}<0$ by Lemma 2, these conditions become

$$
\begin{aligned}
& \frac{d \Pi^{*}}{d \Theta^{*}}-\frac{\delta \gamma_{1} V_{1} p_{11}^{*} \sigma^{2}}{N} \frac{d p_{11}^{*}}{d \Theta^{*}}=0 \\
& \frac{d \Pi^{*}}{d \Theta^{*}}-\frac{\delta \gamma_{2} V_{2} p_{11}^{*} \sigma^{2}}{N} \frac{d p_{11}^{*}}{d \Theta^{*}}=0 .
\end{aligned}
$$

Let $\Theta^{* *}(\phi)=\arg \max _{\Theta^{*}} \Pi^{*}\left(\Theta^{*}\right)$. Since $N_{1}^{*}(\phi) \in(0, N)$, it follows that $\Theta^{* *}(\phi) \in(0,1)$. Thus by continuity, for $\sigma^{2}$ sufficiently small, there will be solutions to these equations, say, $\Theta_{1}^{*}$, $\Theta_{2}^{*} \in(0,1)$. Since these equations are identical except for the factor $\gamma_{l} V_{l}, l=1,2$, and since $\gamma_{1} V_{1} \neq \gamma_{2} V_{2}$, we have $\Theta_{1}^{*} \neq \Theta_{2}^{*}$. Using Lemma 2 , it follows that $N_{11} \neq N_{12}$.

We next show that for $\sigma^{2}$ sufficiently small, $\frac{d \Theta_{l}^{*}}{d \sigma^{2}}>0$. Consider the first of these equations and let $c_{l}=\frac{\delta \gamma_{l} V_{l}}{N}, l=1,2$. Differentiating this equation implicitly with respect to $\sigma^{2}$ yields

$$
\frac{d \Theta^{*}}{d \sigma^{2}}\left[\frac{d^{2} \Pi^{*}}{d \Theta^{*^{2}}}-c_{1} \sigma^{2} p_{11}^{*} \frac{d^{2} p_{11}^{*}}{d \Theta^{*^{2}}}-c_{1} \sigma^{2}\left(\frac{d p_{11}^{*}}{d \Theta^{*}}\right)^{2}\right]=c_{1} p_{11}^{*} \frac{d p_{11}^{*}}{d \Theta^{*}}
$$

Using the definition of $\Pi^{*}$ and rearranging terms produces

$$
\frac{d \Theta^{*}}{d \sigma^{2}}=\left[\left(\Delta_{1}-c_{1} \sigma^{2} p_{11}^{*}\right) \frac{d^{2} p_{11}^{*}}{d \Theta^{*^{2}}}+\Delta_{2} \frac{d^{2} p_{22}^{*}}{d \Theta^{*^{2}}}-c_{1} \sigma^{2}\left(\frac{d p_{11}^{*}}{d \Theta^{*}}\right)^{2}\right]^{-1} c_{1} p_{11}^{*} \frac{d p_{11}^{*}}{d \Theta^{*}} .
$$

Since $p_{i i}^{*}=z_{i}^{*}$ by Corollary 1 , we have, using Lemma 2, that $\Delta_{2} \frac{d^{2} p_{22}^{*}}{d \Theta^{*^{2}}}<0$ and for $\Delta_{1}>0$ (or $r_{1}>0$ ), $\frac{d^{2} p_{11}^{*}}{d \Theta^{*^{2}}}<0$. Furthermore, Lemma 1 also established that $\frac{d p_{11}^{*}}{d \Theta^{*}}<0$. Thus, when $\sigma^{2} \in\left(0, \frac{\Delta_{1}}{c_{1}}\right], \frac{d \Theta_{1}^{*}}{d \sigma^{2}}>0$. Similarly, for the second equation, $\frac{d \Theta_{2}^{*}}{d \sigma^{2}}>0$ when $\sigma^{2} \in\left(0, \frac{\Delta_{1}}{c_{2}}\right]$. Therefore, there will be a constant $c<\min \left[\frac{\Delta_{1}}{c_{1}}, \frac{\Delta_{1}}{c_{2}}\right]$ such that for $\sigma^{2} \in(0, c)$ there will both be a solution to these equations and $\frac{d \Theta_{l}^{*}}{d \sigma^{2}}>0$. Returning to the necessary conditions above, and recalling that $\Pi^{*}$ is concave (Lemma 2) and $\frac{d p_{11}^{*}}{d \Theta^{*}}<0$ (Lemma 1), it now follows that for $\sigma^{2} \in(0, c)$ each solution $\Theta_{l}^{*}$ satisfies $\Theta_{l}^{*}>\Theta^{* *}(\phi)$. Using Lemma 2 again, we have $N_{11}<N_{1}^{*}(\phi)$ and $N_{12}<N_{1}^{*}(\phi)$. 


\subsection{Proof of Theorem 4}

a. Because the objective functions of the $I_{l}$ are bounded with support $[0, V]$, the maximum must occur in this interval. Since $x^{*}=\arg \max _{x}\left[\delta_{1} \frac{x}{N}+\delta_{2} \frac{V-x}{N}\right] \Pi^{*}(x+y)$, the necessary condition for $x^{*}$ to be an interior solution, given the choice of $I_{2}$, is

$$
\frac{\delta_{1}-\delta_{2}}{N} \Pi^{*}\left(N_{1}\right)+\left(\frac{\delta_{1}-\delta_{2}}{N} x+\delta_{2} \frac{V}{N}\right) \frac{d \Pi^{*}\left(N_{1}\right)}{d N_{1}} \frac{\partial N_{1}}{\partial x}=0
$$

where $N_{1}=x+y$. Similarly, the first-order condition for $y^{*}$ is

$$
\frac{\delta_{1}-\delta_{2}}{N} \Pi^{*}\left(N_{1}\right)+\left(\frac{\delta_{1}-\delta_{2}}{N} y+\delta_{2} \frac{V}{N}\right) \frac{d \Pi^{*}\left(N_{1}\right)}{d N_{1}} \frac{\partial N_{1}}{\partial y}=0 .
$$

Since $\frac{\partial N_{1}}{\partial x}=\frac{\partial N_{1}}{\partial y}=1$, the difference of the two equations yields $x^{*}=y^{*}$. Because $N_{1}=x+y$, we have that $x^{*}=y^{*}=\frac{N_{1}^{\circ}}{2}$. To determine $N_{1}^{\circ}$, we note that one half the sum of the two equations, when $x$ and $y$ are each replaced by $\frac{N_{1}}{2}$, becomes $\frac{\delta_{1}-\delta_{2}}{N} \Pi^{*}\left(N_{1}\right)+\left(\frac{\delta_{1}-\delta_{2}}{N} \frac{N_{1}}{2}+\delta_{2} \frac{V}{N}\right) \frac{d \Pi^{*}\left(N_{1}\right)}{d N_{1}}=0$. Since $V=\frac{N}{2}$, this last expression becomes $\frac{\delta_{1}-\delta_{2}}{N} G\left(N_{1}\right)=0$. Thus, $N_{1}^{\circ}$ must satisfy $G\left(N_{1}^{\circ}\right)=0$.

If $N_{1}^{\circ}=0$ then $x^{*}=y^{*}=0$, and if $N_{1}^{\circ}=N$ then $x^{*}=y^{*}=V=\frac{N}{2}$.

b. Let $\delta_{1}>\delta_{2}$. From part a, $N_{1}^{\circ}$ satisfies $\Pi^{*}\left(N_{1}\right)+\frac{N}{2}\left[\frac{N_{1}}{N}+\frac{\delta_{2}}{\delta_{1}-\delta_{2}}\right] \frac{d \Pi^{*}\left(N_{1}\right)}{d N_{1}}=0$. Because $\Pi^{*}>0$, for this equation to be satisfied, $\frac{d \Pi^{*}}{d N_{1}}$ evaluated at $N_{1}^{\circ}$ must be negative. Since $\Delta_{j} \neq 0$ for some $j$, by Lemma $2, N_{1}^{*}$ is the unique value of $N_{1}$ that maximizes $\Pi^{*}\left(N_{1}\right)$ it follows that $N_{1}^{\circ}>N_{1}^{*}$. Let $\delta_{1}<\delta_{2}$. Then since $V=\frac{N}{2},\left[\frac{N_{1}}{2}+\frac{\delta_{2} V}{\delta_{1}-\delta_{2}}\right]=\frac{N}{2}\left[\frac{N_{1}}{N}-\frac{\delta_{2}}{\delta_{2}-\delta_{1}}\right]$ is negative. Therefore for $N_{1}^{\circ}$ to satisfy the equation, $\frac{d \Pi^{*}}{d N_{1}}$ must be positive at $N_{1}^{\circ}$. Again, by the property of $N_{1}^{*}$, it follows that $N_{1}^{\circ}<N_{1}^{*}$. 